\title{
L-Triptofano, ômega 3, magnésio evitaminas do complexo B na diminuição dos sintomas de ansiedade
}

\author{
Eduarda Aparecida Franco de Andrade ${ }^{1}$, Lina Cláudia Sant'Anna ${ }^{2}$, Natalie de Castro Almeida ${ }^{3}$,
} Ivonilce Venturi ${ }^{4}$, Libardone José Ribeiro Brustulim ${ }^{5}$, Wagner Ozório D'Almeida ${ }^{6}$

\begin{abstract}
Resumo: O objetivo deste trabalho foi investigar o potencial ansiolítico do L-triptofano, ômega 3, magnésio e das vitaminas do complexo B em estudantes universitárias com ansiedade. $\mathrm{O}$ estudo teve caráter experimental clínico, randomizado, de abordagem quali-quantitativa e foi composto por 16 estudantes que foram divididas em dois grupos, o grupo controle (GC) que recebeu o tratamento e o grupo placebo (GP) que recebeu apenas ômega 3. Para avaliar o nível de ansiedade aplicou-se a escala Hospitalar de Ansiedade e Depressão (HAD) antes e dias antes do término do tratamento de 35 dias com os nutrientes já citados. Os resultados mostraram que antes do tratamento $100 \%$ das acadêmicas do GC apresentaram provável quadro de ansiedade e após o tratamento $57 \%(\mathrm{p}<0,05)$ foram classificadas com improvável ansiedade e $43 \%$ com possível ansiedade. Em relação ao GP observou-se que antes do tratamento nenhuma das estudantes foi classificada com improvável ansiedade e após o tratamento $57 \%$ $(\mathrm{p}<0,05)$ foram classificadas nessa categoria. A suplementação com L- triptofano, ômega 3, magnésio e vitaminas do complexo B se mostrou eficaz contra os sintomas da ansiedade, assim como o uso do ômega 3 no GP.
\end{abstract}

Palavras-chave: ansiedade, substâncias bioativas, L-triptofano, ômega 3, magnésio, vitaminas do complexo B.

\section{L-Tryptophan, Omega 3, Magnesium and B Complex Vitamins in Reducing Anxiety Symptoms}

\begin{abstract}
The objective of this work was to investigate the anxiolytic potential of L-tryptophan, omega-3, magnesium and B complex vitamins in university students with anxiety. The study was a randomized clinical trial of a qualitative and quantitative approach and was composed of 16 students who were divided into two groups, the control group (CG) who received the treatment and the placebo group (PG) who received only omega 3. To assess the level of anxiety the Hospital Anxiety and Depression (HAD) scale was applied before and days before the end of the 35-day treatment with the nutrients already mentioned. The results showed that before treatment $100 \%$ of CG students had a probable anxiety disorder and $57 \%(\mathrm{p}<0.05)$ were classified with unlikely anxiety and $43 \%$ with possible anxiety. Regarding PG, it was observed that before the treatment none of the students were classified with unlikely anxiety and after treatment $57 \%(\mathrm{p}<0.05)$ were classified in this category. Supplementation with L-tryptophan, omega-3, magnesium and B-complex vitamins was shown to be effective against the symptoms of anxiety, as well as the use of omega-3 in GP.
\end{abstract}

Keywords: anxiety, bioactive substances, L-tryptophan, omega-3, magnesium, Bcomplex vitamins.

\footnotetext{
${ }^{1}$ Nutricionista (UNIGUAÇU). duda.andrade130@gmail.com;

2 Nutricionista (UNIVALI), Mestre em Nutrição, Metabolismo e Dietética (UFSC), Docente do curso de nutrição UNIGUAÇÚ.prof_lina@uniguacu.edu.br;

${ }^{3}$ Psicóloga (UNC), Especialista em Neuropsicologia e Psicologia do Trânsito (CEDETC) Docente do curso de nutrição UNIGUAÇU.prof_natalie@uniguacu.edu.br;

${ }^{4}$ Nutricionista (UNIVALI), Mestre em Ciências da Nutrição (UFV), Doutora em Ciências Farmacêuticas (UNIVALI), Docente do curso de nutrição - UNIGUAÇU. ivonilce.venturi@gmail.com;

${ }^{5}$ Educador Físico (UNIGUAÇU), Licenciado em ciências (FAFI), Especialização em fisiologia do exercício aplicada a saúde (ISPAE), Docente do curso de nutrição - UNIGUAÇÚ.prof_liba@ uniguacu.edu.br

${ }^{6}$ Nutricionista (UNIGUAÇU), Especialista em Nutrição Clínica, Metabolismo, Prática e Terapia Nutricional (Universidade Gama Filho/RJ), Docente do curso de nutrição - UNIGUAÇU Contato: prof_wagneralmeida@ uniguacu.edu.br (42) 35226192, UNIGUAÇU
}

1129 Id on Line Rev. Mult. Psic. V.12, N. 40. 2018 - ISSN 1981-1179

Edição eletrônica em http://idonline.emnuvens.com.br/id 


\section{Introdução}

A ansiedade é vista como uma ameaça ao Ego, pois é semelhante ao medo, Freud descreveu como um temor sem razão, por isso é difícil identificar sua fonte ou o que provocou (SCHULTZ; SCHULTZ, 2014). Os transtornos de ansiedade podem aparecer junto com outras condições clínicas e agir com elas (ROWLAND; PEDLEY, 2011). Os transtornos ansiosos apresentam como sintomas reações fisiológicas, como taquicardia, sudorese ou tontura, falta de memória e atenção, irritação, desespero, excesso de preocupação, retraimento social, diminuição do rendimento escolar ou profissional (SOUZA, 2013).

Estudos tem demonstrado que estados de ansiedade tem relação com a alimentação inadequada, por isso substâncias bioativas ofertadas como suplementação ajudam como forma de tratamento em quadros ansiosos. O consumidor se expõe a uma dose mais elevada de composto(s) bioativo(s) presentes nos alimentos que são ingeridos normalmente na dieta (PINTO, 2010).

Estudos associam a patologia aos sistemas neurotransmissores que aparecem em disfunção (ROWLAND; PEDLEY, 2011). Como o neurotransmissor serotonina (5HT) que é produzido através do aminoácido triptofano, o sistema serotoninérgico exerce um papel importante na função orgânica, como na modulação da motilidade gastrointestinal, função plaquetária, regulação hidroeletrolítica, regulação da sede e apetite, ingestão alimentar, balanço energético e ainda regulação das emoções e de processos comportamentais. (VEDOVATO et al., 2014).

Por sua vez, temos o neurotransmissor melatonina que é sintetizado a partir do hormônio serotonina como resultado da hidroxilação do aminoácido triptofano, este está envolvido na regulação do sono e dos ritmos cicardianos, atualmente a melatonina é considerada um tradutor do ciclo claro-escuro (OLIVEIRA, 2016).

$\mathrm{Na}$ busca de melhorar os sintomas de ansiedade encontramos ainda como auxiliador, os ácidos graxos essenciais como o ômega 3 que em um equilíbrio com Ômega 6 e Ômega 9, estes que são precursores dos eicosanoides mediadores inflamatórios lipossolúveis e de ácido eicosapentanóico (EPA) e ácido docosaexaenoico (DHA), a função nutricional, estrutural e reguladora destes ácidos graxos poli-insaturados tem impacto significativo nas funções fisiológicas do organismo (WAITZBERG, 2015). Pois, a relação de níveis baixos de ômega 3 em estados de depressão e ansiedade aumentam a produção de citocinas próinflamatórias por 
exposição a situações estressantes, sendo assim, o ômega 3 em equilíbrio age por diminuir essas ações inflamatórias (KIECOLT-GLASER et al., 2011).

Para tanto, às vitaminas e minerais são micronutrientes importantes para ajudar na metabolização de macronutrientes e nos seus produtos finais, das quais são o magnésio e vitaminas do complexo $\mathrm{B}$, que também auxiliam na reconstrução de tecidos inclusive no cérebro e sistema nervoso, elas participam na conversão de glicose em energia, na síntese de serotonina e de melatonina (VITOR; PINHÃO, 2014) na ligação hormonal ao receptor, fluxo de íons através das membranas, contração muscular, atividade neuronal, tônus vasomotor, excitabilidade cardíaca, liberação de neurotransmissores (SOUZA, 2013). Por isso o aporte inadequado pode resultar um QI abaixo do seu potencial, memória fraca, cansaço, tonturas, falta de concentração, falta de motivação e depressão (VITOR; PINHÃO, 2014).

Este trabalho teve como objetivo avaliar a eficácia do consumo das substâncias bioativas L-triptofano, Ômega 3, magnésio e vitaminas do complexo B na melhora dos sintomas de ansiedade em acadêmicas do curso de nutrição de uma instituição privada de Ensino Superior de União da Vitoria - PR.

\section{Metodologia}

A presente pesquisa tratou-se de um estudo clínico randomizado, com amostragem não probabilística intencional. O trabalho foi aprovado ( $N^{\circ}$ 2017/235) pelo Núcleo de Ética em Pesquisa com seres Humanos da UNIGUAÇU. Todos os indivíduos envolvidos na pesquisa receberam o termo de consentimento livre e esclarecido (TCLE), sendo esclarecidos todos os riscos e benefícios e seu direito de se retirar da pesquisa a qualquer momento sem prejuízo a sua integridade. Foi garantida a assistência integral, imediata e gratuita. Utilizou-se como critérios de exclusão estar fazendo tratamento ou uso de medicamentos para ansiedade ou depressão ou já ter realizado tratamento anterior.

Inicialmente 21 acadêmicas com idades entre 19 e 30 anos foram voluntárias para a pesquisa, foi avaliado o nível de ansiedade utilizando-se a escala Hospitalar de Ansiedade e Depressão (HAD) proposta pela Universidade Estadual Paulista (UNESP) (ZIGMOND et al., 1995). Este protocolo utiliza uma escala que varia de 0 a 21 pontos, no qual de 0 a 7 pontos é considerada como improvável para ansiedade, de 8 a 11 pontos como possível quadro de 
ansiedade e acima de 12 pontos como provável ansiedade. O protocolo foi aplicado a todas as 21 acadêmicas, das quais 5 não apresentaram quadro de ansiedade, sendo excluídas da amostra.

As acadêmicas que foram pontuadas com possível ou provável quadro de ansiedade foram alocadas aleatoriamente em dois grupos, sendo um grupo controle que recebeu a suplementação (8 acadêmicas) e outro grupo placebo que recebeu apenas ômega 3 (8 acadêmicas). Os indivíduos não tinham conhecimento de qual grupo estavam participando, garantindo assim, possíveis interferências emocionais. Até o final da pesquisa 2 acadêmicas se retiraram voluntariamente, tendo ao final 7 indivíduos em cada grupo.

A suplementação oferecida ao grupo controle foi composta por L-triptofano (500 mg), Ômega 3 (1100 mg), Magnésio (310 mg), Vitamina B1 (0,9 mg), B2 (1,1 mg), B3 (16 mg), B5 (5 mg), B6 (1,3 mg), B7 (30 mcg), B9 (400 mcg) e B12 (2,4 mcg). Esta suplementação foi preparada com base nas Dietary Reference Intakes (DRI) para mulheres de 19 a 30 anos de idade. A suplementação foi oferecida em forma de cápsula aos participantes da pesquisa. $\mathrm{O}$ grupo placebo recebeu cápsula contendo apenas Ômega $3(1000 \mathrm{mg})$. Foi orientado que a cápsula fosse ingerida com $200 \mathrm{ml}$ de água, após o almoço, durante 5 semanas (35 dias).

Após o período de tratamento os indivíduos foram avaliados novamente com a escala HAD para verificar se ocorreu modificação no estado de ansiedade após a suplementação.

Os dados foram analisados pelo software Statistic 5.0, foi adotado um nível de significância de $95 \%$ com erro de $5 \%$. Para a comparação entre os grupos foi utilizado o teste $t$.

\section{Resultados e Discussões}

A Escala Hospitalar de Ansiedade e Depressão (HAD) avalia a ansiedade em diferentes níveis, correlacionando com o bem-estar emocional, físico e funcional de um indivíduo. Níveis altos de ansiedade interferem negativamente na qualidade de vida de um indivíduo.

Neste estudo foi possível observar (Tabela 01) melhora significativa $(p<0,005)$ no quadro de ansiedade dos indivíduos estudados, tanto do grupo controle o qual recebeu uma suplementação quanto o que recebeu apenas ômega 3. 
Tabela 01. Resultados da avaliação pela Escala Hospitalar de Ansiedade e Depressão (HAD) aplicada antes e após a suplementação nutricional em um grupo de estudantes.

\begin{tabular}{ccccc} 
& \multicolumn{2}{c}{ Placebo } & \multicolumn{2}{c}{ Controle } \\
\cline { 2 - 5 } Sintomas & Antes & Após & Antes & Após \\
\hline Improvável & $0(0 \%)$ & $4(57 \%)^{*}$ & $0(0 \%)$ & $4(57 \%)^{*}$ \\
Possível & $6(71 \%)$ & $3(43 \%)$ & $0(0 \%)$ & $3(43 \%)$ \\
Provável & $2(29 \%)$ & $0(0 \%)$ & $8(100 \%)$ & $0(0 \%)$ \\
\hline
\end{tabular}

Fonte: Dados coletados pela autora.

Legenda: * diferença estatisticamente significante entre o antes e após suplementação.

Importante observar que entre as falas das pesquisadas estavam "deixei de agir e sentir coisas prejudiciais que interferiam no meu bem estar"; "estou me sentindo mais calma", "estou menos irritada", "estou tendo menos fome", "tenho menos vontade de comer doces e porcarias", "tenho mais disposição para fazer as coisas", "estou conseguindo me concentrar melhor nas aulas", "durmo melhor" e "não roo mais as unhas", estas falas ocorreram nos dois grupos, podendo-se observar que tanto a suplementação com os compostos bioativos como o L-triptofano, ômega 3, o magnésio e vitaminas do complexo B ou somente a suplementação de ômega 3 auxiliam na melhora dos sintomas de ansiedade.

Vitaminas do complexo B estão associados à melhora de quadros de declínio cognitivo, assim como, reduzem as condições de demência e Alzheimer (MIKKELSEN et al., 2016).

Estudo de revisão de literatura demonstra que o triptofano está relacionado à melhora do controle sobre o comportamento social em indivíduos que sofrem de distúrbios associados a disfunções no funcionamento serotoninérgico (STEENBERGEN, et al., 2016).

Elbaz e Hanafy (2016) explicam que estudos demonstraram os efeitos do magnésio na aprendizagem e na memória nos seres humanos e sua deficiência foi associada com função cognitiva deficiente e baixo nível acadêmico e a falta de magnésio estava relacionada à desatenção, retardo mental e problemas de fala.

Baza et al. (2016) realizaram suplementação de magnésio em crianças com transtorno de atenção e hiperatividade verificando a melhora do quadro quando suplementadas com o magnésio, melhorando as funções cognitivas. Ordak et al. (2017) descrevem a importância da suplementação do magnésio para aumentar a eficácia do tratamento farmacológico. Sartori et al. (2012) testaram em camundongos as alterações no eixo hipotálamo-hipófise-adrenal contribuindo para a hiper-emocionalidade causadas pela deficiência de magnésio, estas alterações levam a comportamentos de ansiedade relacionadas à deficiência de magnésio. $\mathrm{O}$ 
tratamento com magnésio demonstrou efeitos benéficos na melhora do quadro de ansiedade em camundongos. Estudo semelhante a este foi realizado por Zanello (2012) o qual utilizou apenas a suplementação com L-triptofano observando diminuição do quadro ansioso dos participantes da pesquisa incluindo a diminuição da compulsão alimentar.

Cortes et al., (2013) realizaram um estudo com animais utilizando uma dieta pobre em ômega 3, observou a relação entre a deficiência do ácido graxo e o quadro ansioso nos animais, sendo que nos animais que foi realizada a suplementação foi observada melhora do quadro ansioso.

Todos os nutrientes inseridos na suplementação possuem funções relacionadas à melhora do quadro ansioso, a realização do estudo se fundamentou nas evidências clínicas de utilização de substâncias bioativas na diminuição dos sintomas da ansiedade, podendo tornarse um tratamento alternativo nos indivíduos com ansiedade.

Estes dados demonstram que a suplementação nutricional foi eficiente na melhora do quadro de ansiedade nas acadêmicas estudadas, podendo este estudo ser repetido em outras amostras.

\section{Conclusão}

A administração via oral da associação do L-triptofano, ômega 3, magnésio e vitaminas do complexo B se mostrou tão eficiente quanto a administração do ômega 3 na redução dos sintomas da ansiedade na amostra estudada. No entanto, estudos com maior tempo de duração, diferentes doses e inclusão do sexo masculino se fazem necessários para confirmar o efeito ansiolítico das substâncias testadas.

O nutricionista é o profissional habilitado para prescrever uma alimentação saudável e balanceada, que vise sempre melhorar a qualidade de vida e assegurar o bem estar de um paciente. Conhecer as necessidades do paciente em relação aos comportamentos ligados às funções cognitivas e emocionais, podem auxiliar o nutricionista na prescrição de uma dieta mais adequada.

Esses resultados apontam a necessidade da realização de ações de educação nutricional voltadas ao incentivo no consumo de alimentos que contenham os nutrientes testados, visando melhorar a qualidade de vida de pacientes com quadro de ansiedade. 


\section{Referências}

ANDRADE, R.V et al. Atuação dos Neurotransmissores na Depressão. Revista Brasileira das Ciências Farmacêuticas v.1, $\mathrm{n}^{\circ} .1, \quad \mathrm{Jan} / \mathrm{Mar}$ 2003. Disponível em < http://www.saudeemovimento.com.br/revista/artigos/cienciafarmaceuticas/v1n1a6.pdf > Acesso em: 16 Mar.2017.

BARBALHO, S. M. et al. Papel dos ácidos graxos ômega 3 na resolução dos processos inflamatórios., Ribeirão Preto, p.234-240, 2011. Anual. Disponível em

< http://www.revistas.usp.br/rmrp/article/view/47365/51102 > acesso em 13 Mar 2017.

BARBOSA, K.B.F et al. Ácidos graxos das séries ômega 3 e 6 e suas implicações na saúde humana. Nutrire. Revista da Sociedade Brasileira de Alimentação e Nutrição, São Paulo, v. 32, n. 2, p.129-145, 2007.

BAZA, Farida El et al. Magnesium supplementation in children with attention deficit hyperactivity disorder. Egyptian Journal Of Medical Human Genetics, v. 17, n. 1, p.63-70, jan. 2016. Elsevier BV. http://dx.doi.org/10.1016/j.ejmhg.2015.05.008.

BITO, Tomohiro et al. Vitamin B 12 deficiency results in severe oxidative stress, leading to memory retention impairment in Caenorhabditis elegans. Redox Biology, v. 11, p.21-29, abr. 2017. Elsevier BV. http://dx.doi.org/10.1016/j.redox.2016.10.013.

BRASIL, Nações Unidas no Brasil. Depressão afeta mais de 300 milhões de pessoas e é doença que mais incapacita pacientes, diz OMS. 2017. Disponível em:

$<\mathrm{https}$ ///nacoesunidas.org/depressao-afeta-mais-de-300-milhoes-de-pessoas-e-e-doencaquemais-incapacita-pacientes-diz-oms/ > . Acesso em: 21 abr. 2017.

CORDIOLI, A.V. et al., DSM-5. 5 ed. Porto Alegre: Artemed, 2014.

CORTES, M. L. et al. Uso de terapêutica com ácidos graxos ômega-3 em pacientes com dor crônica e sintomas ansiosos e depressivos. Revista Dor, São Paulo, v. 14, n. 1, p.48-51, 2013. Bimestral. Disponível em < http://dx.doi.org/10.1590/S1806-00132013000100012 > Acesso em 14 Mar 2017.

DALGALARRONDO, P. Psicopatologia e semiologia dos transtornos mentais. 2. ed. Porto Alegre: Artmed, 2008.

DIAS, E. V; SARTORI, C. R. Compreendendo o Efeito Placebo. Revista Ciências em Saúde, São Paulo, v. 5, n. 4, p.1-12, dez. 2015. Disponível em $<$ http://200.216.240.50:8484/rcsfmit/ojs-2.3.3-

3/index.php/rcsfmit_zero/article/viewFile/399/275> Acesso em 21 Set 2017.

DOUGLAS, C. R. Fisiologia aplicada a nutrição. 2. ed. Rio de Janeiro: Guanabara Koogan, 2006.

\section{Id on Line Rev. Mult. Psic. V.12, N. 40., 2018 - ISSN 1981-1179} Edição eletrônica em http://idonline.emnuvens.com.br/id 
ELBAZ, Farida; ZAHRA, Sally; HANAFY, Hussien. Magnesium, zinc and copper estimation in children with attention deficit hyperactivity disorder (ADHD). Egyptian Journal Of Medical Human Genetics, v. 18, n. 2, p.153-163, abr. 2017. Elsevier BV. http://dx.doi.org/10.1016/j.ejmhg.2016.04.009.

ELTONY, Sohair A.. Histological study on the protective role of vitamin B complex on the cerebellum of diabetic rat. Tissue And Cell, [s.1.], v. 48, n. 4, p.283-296, ago. 2016. Elsevier BV.http://dx.doi.org/10.1016/j.tice.2016.06.009.

GIBNEY, M. J. (Ed.);VORSTER, H. H. (Edit.);KOK, F. J. Introdução à nutrição humana. Rio de Janeiro, Guanabara, 2005.

GONZALES, Elisa et al. Omega-3 fatty acids improve behavioral coping to stress in multiparous rats. Behavioural Brain Research, v. 279, p.129-138, fev. 2015. Elsevier BV. http://dx.doi.org/10.1016/j.bbr.2014.11.010.

GROPPER, S. S. Nutrição avançada e metabolismo humano. 5. ed. São Paulo: Cencage Learning, 2011.

GUYTON, A. C. Fisiologia Humana. 6 ed. Rio de Janeiro: Guanabara Koogan, 2011. I.KAPLAN, Harold; SADOCK, Benjamin J.; GREB, Jack A.. Compêndio de psiquiatria: ciências do comportamento e psiquiatria clínica. 7. ed. Porto Alegre: Artmed, 1997.

HELKIS, H; GATTAZ, W. F. Algumas recomendações para estudos com placebo. Revista Brasileira de Psiquiatria, São Paulo, v. 22, n. 4, p.1-5, dez. 2000. Disponível em < http://www.scielo.br/scielo.php?script=sci_arttext\&pid=S1516-44462000000400001> Acesso em 20 Set 2017.

KIECOLT-GLASER, Janice K. et al. Omega-3 supplementation lowers inflammation and anxiety in medical students: A randomized controlled trial. Brain, Behavior, And Immunity, v. 25, n. 8, p.1725-1734, nov. 2011. Elsevier BV. http://dx.doi.org/10.1016/j.bbi.2011.07.229.

LIRA, C. R. G. et al. Nutracêuticos: aspectos sobre segurança, controle de qualidade e legislação. Revista Brasileira de Farmácia, Florianópolis - SC, v. 90, n. 1, p.45-49, 05 mar. 2009. Disponível em <www.rbfarma.org.br/files/pag_45a49_180_nutraceuticos.pdf> acesso em 04 Jul 2017.

MAHAN, L. K.; ESCOTT-STUMP, S.; RAYMOND, J. L. Krause: alimentos, nutrição e dietoterapia. 13. ed. Rio de Janeiro: Elsevier, 2012.

MARANGON, A. F. C.; ZANELlO, D. R. de P. Efeitos do L- Triptofano sobre ansiedade, compulsão e escolha alimentar. 2012. 27 f. TCC (Graduação) - Curso de Nutrição, Centro Tecnológico, Centro Universitário de Brasília, Brasília, 2012. Cap. 1. Disponível em < http://repositorio.uniceub.br/handle/235/7287 > Acesso em: 14 Mar 2017. 
MARTINS, A. C. C. L. Determinação de Precursores da Serotonina - Triptofano e 5hidroxitriptofano - em Café por CLAE-par IÔNICO. 2008. 98 f. Dissertação (Mestrado) Curso de Ciências dos Alimentos, Centro Tecnológico, Faculdade de Farmácia da Universidade Federal de Minas Gerais, Belo Horizonte, 2008.

MIKKELSEN, Kathleen et al. Cognitive decline: A vitamin B perspective. Maturitas, v. 93, p.108-113, nov. 2016. Elsevier BV. http://dx.doi.org/10.1016/j.maturitas.2016.08.001.

OLIVEIRA, S. J. R. de. Sono, melatonina e exercício físico. 2016. 96 f. Dissertação (Mestrado) - Curso de Ciências Farmacêuticas, Faculdade das Ciências da Saúde, Universidade Fernando Pessoa, Porto, 2016. Disponível em <http://bdigital.ufp.pt/handle/10284/5828>. Acesso em 18 Abr 2017.

ORDAK, Michal et al. Magnesium in schizophrenia. Pharmacological Reports, v. 69, n. 5, p.929-934, out. 2017. Elsevier BV. http://dx.doi.org/10.1016/j.pharep.2017.03.022.

PALERMO, J. R. Bioquímica da nutrição. São Paulo, Atheneu, 2008.

PENTEADO, M. V. C. Vitaminas: Aspectos nutricionais, bioquímicos, clínicos e analíticos. São Paulo, Manole, 2003.

PINTO, J. F. Nutracêuticos e alimentos funcionais. Portugal, LIDEL, 2010.

RAJIZADEH, Afsaneh et al. Effect of magnesium supplementation on depression status in depressed patients with magnesium deficiency: A randomized, double-blind, placebocontrolled trial. Nutrition, [s.1.], v. 35, p.56-60, mar. 2017. Elsevier BV. http://dx.doi.org/10.1016/j.nut.2016.10.014.

ROWLAND, L. P.; PEDLEY, T. A. Tratado de Neurologia. 12. ed. Rio de Janeiro: Guanabara Koogan, 2011.

SARTORI, S.b. et al. Magnesium deficiency induces anxiety and HPA axis dysregulation: Modulation by therapeutic drug treatment. Neuropharmacology, v. 62, n. 1, p.304-312, jan. 2012. Elsevier BV. http://dx.doi.org/10.1016/j.neuropharm.2011.07.027

STEENBERGEN, Laura et al. Tryptophan supplementation modulates social behavior: A review. Neuroscience \& Biobehavioral Reviews, v. 64, p.346-358, maio 2016. Elsevier BV. http://dx.doi.org/10.1016/j.neubiorev.2016.02.022.

SCHUlTZ, D.; SCHULTZ, S. E. Teorias da Personalidade. 2. ed. Rio de Janeiro: Cencage Learning, 2014.

SEZINI, A. M.; GIL, C. S. G. do C. Nutrientes e Depressão. Revista da Faculdade União de Goyazes, Trindade-go, v. 8, n. 1, p.39-57, 2014. Anual. Disponível em < http://www.fug.edu.br/revista/index.php/VitaetSanitas/article/view/29 > Acesso em 13 Mar 2017. 
SOUSA, B. S. de. Investigação do potencial ansiolítico de magnésio e Vitamina B6 em uma única administração em humanos. 2013. 73 f. TCC (Graduação) - Curso de Nutrição, Centro de Ciências da Saúde, Universidade Federal da Paraíba - Ufpb, João Pessoa, 2013.

SOUZA, A. C. S. de et al. Riboflavina: uma vitamina multifuncional. Química Nova, Campinas - SP, v. 28, n. 5, p.887-891, abr. 2005.

Disponível em:

<http://www.scielo.br/pdf/\%0D/qn/v28n5/25919.pdf> acesso em: 18 Abr 2017.

VAZ, D. S. S. et al. A importância do ômega 3 para a saúde humana: um estudo de revisão. Revista UNINGÁ Review, Apucarana, Paraná, Brasil, v. 20, n. 2, p.48-54,

2014. Bimestral. Disponível em < http://www.mastereditora.com.br/periodico/20141103_154429.pdf > Acesso em 12 Mar 2017.

VEDOVATO, K. et al. O eixo intestino-cérebro e o papel da serotonina. Arquivos de Ciências de Saúde da Unipar, Umuarama, v. 18, n. 1, p.33-42, abr. 2014. Disponível em: <http://www.revistas.unipar.br/index.php/saude/article/view/5156>. Acesso em 18 Abr 2017.

VITOR, R. F.; PINHÃO, S. Terapêuticas Nutricionais na promoção da estabilidade emocional e desenvolvimento cognitivo. Cadernos de Investigação Aplicada, Campo Grande, p.55-74, nov. 2014. Disponível em:

<http://recil.grupolusofona.pt/bitstream/handle/10437/7360/terapeuticas_nutricionais_p5574.pdf? sequence=1>. Acesso em 20 Abr 2017.

WAITZBERG, D. L. Ômega 3: o que existe de concreto. Researchgate, São Paulo, v. 1, n. 1, p.1-37, 08 jul. 2015. Disponível em

<https://www.researchgate.net/publication/265874955_Omega3_o_que_existe_de_concreto> acesso em 17 Abr 2017.

ZANELLO, D. R. de P. Efeitos do L-triptofano sobre ansiedade, compulsão e escolha alimentar. 2012. 27 f. TCC (Graduação) - Curso de Nutrição, Centro Universitário de Brasília - Uniceub, Faculdades das Ciências da Educação e Saúde -faces, Brasília, 2012.

Disponível em:

<http://repositorio.uniceub.br/bitstream/235/7287/1/Diogo\%20Rabelo\%20de\%20Paula\%20Z a nello.pdf.> Acesso em: 17 Abr 2017.

\section{Como citar este artigo (Formato ABNT):}

ANDRADE, Eduarda Aparecida F. de; SANT'ANNA, Lina Cláudia; ALMEIDA, Natalie de Castro; VENTURI, Ivonilce; BRUSTULIM, Libardone José R.; D'ALMEIDA, Wagner O. L-Triptofano, ômega 3, magnésio evitaminas do complexo B na diminuição dos sintomas de ansiedade. Id on Line Revista Multidisciplinar e de Psicologia, 2018, vol.12, n.40, p.1129-1138. ISSN: 19811179.

Recebido: 28.05 .2018

Aceito: 29.05 .2018 